\title{
PROFITABILITY OF CAPM MOMENTUM STRATEGIES IN THE US STOCK MARKET
}

\author{
Terence Tai-Leung Chong* \\ The Chinese University of Hong Kong \\ Qing He \\ Renmin University of China \\ Hugo Tak-Sang Ip \\ The Chinese University of Hong Kong \\ Jonathan T. Siu \\ The Chinese University of Hong Kong
}

\begin{abstract}
This paper provides a historical review of the performance of the risk-adjusted momentum strategies when buying and selling stocks according to the alpha estimates of the CAPM and Fama-French regressions. Our sample covers over 60 million US daily firm-return observations. High Sharpe ratios are obtained under our risk-adjusted strategies. It is also found that stock market crashes have no apparent impact on our momentum profits.
\end{abstract}

Keywords: Momentum Strategies; Sharpe Ratio; Fama-French Model; CAPM Model.

\section{INTRODUCTION}

The momentum trading strategy has received increasing academic attention over the past two decades since the pioneering work of Jegadeesh and Titman (1993), who show that strategies of long winner stocks and short loser stocks over the past 3 to 12 months generate a monthly return of 1 percent in the US market. Similarly, Chan et al.(2000) find the existence of momentum profits in 23 international stock markets. Chong and Ip (2009) show that momentum profits exist in emerging currency markets. However, a debate still remains concerning the source of the profits and the interpretation of momentum profits. Risk-based explanations argue that momentum profits result from exposures to certain risk variables that are not priced in the traditional models of expected returns. For instance, Daniel and Titman (1999) argue that firms with high market-to-book ratios produce enhanced momentum profits. Grinblatt and Moskowitz (1999) suggest that the momentum profits can be attributed to the industry effect. Chordia and Shivakumar (2002) find evidence that macroeconomic factors perform well in capturing the variation of momentum profits. Grinblatt and Moskowitz (2003) show that growth firms have a higher momentum effect. Sagi and Seasholes (2007) identify a variety of observable firm-specific attributes that drive momentum profits. In contrast, the behavioural explanations by Barberis et al. (1998), Daniel et al. (1998) and Hong and Stein (1999) show that cognitive biases lead investors to underreact to new information, contributing to the persistent profits of the momentum trading strategy.

\footnotetext{
* Corresponding Author: Terence Tai-Leung Chong, Department of Economics, The Chinese University of Hong Kong, Shatin, N.T., Hong Kong. Email: chong2064@ cuhk.edu.hk. Phone (852)39431614. Webpage: http://www.cuhk.edu.hk/eco/staff/tlchong/tlchong3.htm.
} 
The empirical evidence lends support to these behavioural models as well. Fama and French (2004) demonstrate that their three-factor models cannot explain the profits of the momentum strategy. Jegadeesh and Titman (2001) show that momentum profits quickly dissipate after the investment period. Grundy and Martin (2001) and Lewellen (2002) argue that the industry effect cannot fully explain the momentum of individual stocks.

An explanation for the mixed empirical evidence is that previous studies select winner and loser stocks according to their past returns, without taking risks into account. Winner stocks may have higher market sensitivity and will rise more dramatically than the low-beta stocks when the market rallies. In addition, the difference in past returns may be due to firm-specific factors such as the firm size and book-tomarket ratio. Jegadeesh and Titman (1993) point out that past stock returns could potentially contain risk factors that would continue to affect the future stock returns. Therefore, a better way to test momentum profits is to rank stocks according to returns adjusted by the market- and firm-specific risks. In this paper, we examine the performance of risk-adjusted momentum strategies in order to shed light on the competing hypothesis for momentum profits. The strategy differs from the existing momentum strategy in that it selects past winners and losers by considering the risk-adjusted returns. Specifically, we examine the risk-adjusted momentum strategies that buy and sell stocks according to the alpha estimates of the CAPM and Fama and French $(1993,1996)$ models. Since the trading strategy is constructed according to risk-adjusted returns, it is less influenced by market- and firm-specific risks. Hence, we can examine whether risk-adjusted momentum strategies wash away conventional momentum profits, as expected by the risk-based explanations, or remain persistently profitable, which is consistent with the behavioural explanations.

Our results show that the momentum profits based on risk-adjusted returns are significant and positively associated with the alphas. In particular, the mean momentum profit is $0.06142 \%$ per day, which is equivalent to an annualized return of $16 \%$. The risk-adjusted momentum portfolio profits are persistent even in the down market. To gain a better understanding of what might be driving the risk-adjusted momentum, we extend our analyses by studying the sub-periods, for which the risk-adjusted momentum profits are still significant. The results suggest that market- and firm-specific risks are not plausible explanations for the persistence of the momentum effects. The momentum is more likely to be due to investors' behaviour bias, which is consistent with the findings of Jegadeesh and Titman (2002).

The remainder of this paper is organized as follows: Section 2 provides a brief description of the data and the methodology applied in this study. Section 3 presents the main results. Section 4 checks the robustness of the results. Section 5 concludes the paper.

\section{DATA AND METHODOLOGY}

The daily returns (including dividend distributions) and delisting returns of stocks listed on the New York Stock Exchange (NYSE), American Stock Exchange (AMEX) and NASDAQ over the sample period of July 1963 to December 2013 are sourced from the CRSP daily return file. Since the US stock market keeps rising after the implementation of three rounds of quantitative easing starting from March of 2009, we exclude the data after the year 2008 to avoid the influence of the quantitative easing policy on our results. Our sample contains 60 million daily firm-return observations. The risk-free rates (onemonth Treasury bill rates), the Fama-French HML and SMB factors and the excess market returns (value-weighted returns on all the NYSE, AMEX and NASDAQ stocks minus the one-month Treasury bill rate) on a daily basis over the same sample period are obtained from the data library website of 
Kenneth French. ${ }^{5}$ The stocks in the sample include ordinary common shares of companies, American trust components, closed-end funds and real estate investment trusts. Following Jegadeesh and Titman (2002), we exclude certificates, American depository receipts, shares of beneficial interest and units. At the end of each month, the coefficients from the capital asset pricing model (CAPM) are assessed. The stocks priced below US\$5 and those with a market capitalization in the lowest NYSE decile at the beginning of the holding period are excluded in order to ensure that the results will not be driven by small and illiquid stocks or by bid-ask bounce.

$$
R_{i}-R_{f}=\alpha_{i}+\beta_{i m}\left(R_{m}-R_{f}\right)+\varepsilon_{i}
$$

and the Fama-French three-factor model

$$
R_{i}-R_{f}=\alpha_{i}+\beta_{i m}\left(R_{m}-R_{f}\right)+\beta_{i s} S M B+\beta_{i v} H M L+\varepsilon_{i}
$$

where $R_{i}$ is the return on the asset, $R_{f}$ is the risk-free rate of interest, $R_{m}$ is the return of the market, $S M B$ measures the excess returns of small caps over big caps, and $H M L$ measures the excess returns of value stocks over growth stocks.

Table 1: Descriptive Statistics of the Entire Sample from Jul 1963 to Dec 2013

\begin{tabular}{cccccc}
\hline \hline Variable & Observation & Mean & Std. Dev. & Max & Min \\
\hline Daily Return & 67072272 & $0.08416 \%$ & $4.52975 \%$ & $1900 \%$ & $-97.16981 \%$ \\
\hline Before excluding stocks priced below \$5 or with market capitalizations that would place them in the smallest \\
& NYSE decile at the beginning of the holding period \\
\hline CAPM Alpha & 3020278 & $0.05012 \%$ & $0.37584 \%$ & $27.19430 \%$ & $-4.99827 \%$ \\
CAPM Beta & 3020278 & 0.67103 & 0.72456 & 34.04399 & -21.21435 \\
Fama-French Alpha & 3020278 & $0.04157 \%$ & $0.34848 \%$ & $29.84355 \%$ & $-4.78543 \%$ \\
Fama-French Market Beta & 3020278 & 0.95826 & 0.96161 & 29.21953 & -34.39162 \\
Fama-French SMB Beta & 3020278 & 0.74259 & 1.20356 & 36.88207 & -37.33255 \\
Fama-French HML Beta & 3020278 & 0.20005 & 1.22412 & 58.57404 & -59.10562 \\
\hline After excluding stocks priced below $\$ 5$ or with market capitalizations that would place them in the smallest NYSE \\
\multicolumn{5}{c}{ decile at the beginning of the holding period } \\
\hline CAPM Alpha & 2195146 & $0.05273 \%$ & $0.25964 \%$ & $12.48382 \%$ & $-1.61093 \%$ \\
CAPM Beta & 2195146 & 0.74280 & 0.69597 & 16.53343 & -6.12895 \\
Fama-French Alpha & 2195146 & $0.04120 \%$ & $0.23012 \%$ & $13.22412 \%$ & $-1.90341 \%$ \\
Fama-French Market Beta & 2195146 & 0.87933 & 0.76119 & 14.56102 & -8.60127 \\
Fama-French SMB Beta & 2195146 & 0.65932 & 0.99162 & 26.69039 & -13.92743 \\
Fama-French HML Beta & 2195146 & 0.19564 & 1.10121 & 32.27334 & -24.02874 \\
Past 6-Month Return & 2209755 & $11.72602 \%$ & $34.89612 \%$ & $4142.85719 \%$ & $-94.92592 \%$ \\
\hline \hline
\end{tabular}

Table 1 reports the descriptive statistics of the aforementioned variables before and after the exclusion of small and illiquid stocks. At the end of each month, all the stocks are ranked according to three different measures, namely the return of the previous six months, the CAPM alpha and the Fama-French alpha (Month -5 to Month 0). We then group the stocks into 10 equally weighted portfolios. Each portfolio is held for six subsequent months of the holding period (Month 1 to Month 6).

\footnotetext{
${ }^{5}$ http://mba.tuck.dartmouth.edu/pages/faculty/ken.french/data_library.html.
} 


\subsection{Portfolio Construction}

Suppose that there are $\mathrm{N}$ stocks in the sample at the end of month 0 . We rank the stocks by (i) the return of the previous six months, (ii) the CAPM alpha and (iii) the Fama-French alpha and construct portfolios P1, P2, .., P10. Portfolio P1 contains the stocks with the highest ranking, i.e., from the 1st to the $r(N / 10)$-th, where $r(m)$ is the integer nearest to $\mathrm{m}$. Similarly, portfolio P2 contains the stocks with the second-highest ranking, i.e., from the $[\mathrm{r}(\mathrm{N} / 10)+1]$-th to the $\mathrm{r}(2 \mathrm{~N} / 10)$-th, and so on. P10 contains the stocks with the lowest ranking, i.e., from the $[\mathrm{r}(9 \mathrm{~N} / 10)+1]$-th to the $\mathrm{N}$-th. Besides the portfolios formed above, a market-neutral portfolio (MNP) is also constructed by buying portfolio P1 and short selling portfolio P10 with the same notional value.

At the end of the six-month holding period, the fund for each portfolio will be allocated to a new portfolio constructed according to the latest ranking. For $i=1, \ldots, 10$, the fund that initially buys portfolio $\mathrm{Pi}$ according to the ranking at the end of December 1963 and holds the portfolio until June 1964 will be invested in a new portfolio Pi according to the ranking at the end of June 1964. This process will continue and the fund will only be reallocated at the end of June and December every year. For simplicity, we refer to this as the rolling-over portfolio Dec-Jun Pi. To avoid the seasonal effect in DecJun Pi, we also construct five other rolling-over portfolios: Jan-Jul Pi, Feb-Aug Pi, Mar-Sep Pi, AprOct Pi and May-Nov Pi. Finally, we construct a composite Pi, which puts equal weights on these six rolling-over portfolios. Special treatment is needed when rolling over the market-neutral portfolio MNP. At the end of each holding period, the values of portfolio P1 and P10 may change and the return on portfolio MNP is the notional return of portfolio P1 minus that of portfolio P10. We add the return to the original notional value of portfolio MNP and roll over to the new portfolio MNP with a new notional value. For example, suppose that the notional value of portfolio MNP is $\$ 100$ at the end of December 1964 , i.e., the corresponding fund buys $\$ 100$ of portfolio P1 and short sells $\$ 100$ of portfolio P10, and if the values of portfolios P1 and P10 have increased by $20 \%$ and 5\%, respectively, during the 6 months, then the new notional value of portfolio MNP would be $\$ 100 \times(1+20 \%-5 \%)=\$ 115$, and the fund would buy $\$ 115$ of portfolio P1, short sell $\$ 115$ of portfolio P10, and hold the portfolios for the following 6 months. For stocks that are delisted during the 6-month holding period, the new price quote will be used to calculate the delisting return if the delisted company is relisted on another exchange. The delisting returns are assumed to be realized on the last trading day. For the sake of simplicity, the delisting returns will not be reinvested until the day of reallocation.

\subsection{Rebalancing and Performance Measure}

The stocks in any portfolio are weighted equally at the beginning of each holding period and there is no rebalancing within the holding period. ${ }^{6}$. The portfolios hold stocks with equal dollar amounts at the beginning of the six-month holding period. After the first trading day, the stocks in the portfolio will have different weights, depending on their prices on each trading day. As a result, the return on each portfolio is generally not equal to the equally weighted average return of the stocks in the portfolio.

$$
C R_{j, T_{0}, T}=\prod_{t=T_{0}}^{T}\left(1+r_{j, t}\right)-1
$$

\footnotetext{
${ }^{6}$ Lesmond et al. (2004) suggest that momentum profits cannot be realized after accounting for transaction costs. To reduce the effect of transaction costs, the portfolios will not be rebalanced within the holding period.
} 
where $r_{j, t}$ is the daily return of the $j$-th stock on day $t$. The cumulative return of portfolio $P i$ is defined as

$C R\left(P i, T_{0}, T\right)=\frac{1}{N} \sum_{j=1}^{N_{t}}\left(1+C R_{j, T_{0}, T}\right)-1=\frac{1}{N} \sum_{j=1}^{N_{t}}\left[\prod_{t=T_{0}}^{T}\left(1+r_{j, t}\right)\right]-1$,

where $N_{i}$ is the number of stocks in portfolio $P_{i}$, and $r_{j, t}$ is the daily return of the $j$-th stock on day $t$.

Suppose the dollar value of portfolio $P_{i}$ on day $T_{0}$ is $\$ 1$. On day $T-1$, its dollar value will become $\$$ [1 $\left.+\mathrm{CR}\left(P_{i}, T_{0}, T-1\right)\right]$. The daily return of portfolio $P_{i}$ on day $T$ is computed as

$r(P i, T)=\frac{C R\left(P i, T_{0}, T\right)-C R\left(P i, T_{0}, T-1\right)}{1+C R\left(P i, T_{0}, T-1\right)}$

where $\mathrm{CR}\left(P_{i}, T_{0}, T-1\right)$. For the market-neutral portfolio, the cumulative return from day $T_{0}$ to day $T$ and the daily return on day $T$ are

$$
C R\left(M N P, T_{0}, T\right)=C R\left(P i, T_{0}, T\right)-C R\left(P i, T_{0}, T-1\right)
$$

and

$$
r(M N P, T)=\frac{C R\left(M N P, T_{0}, T\right)-C R\left(M N P, T_{0}, T-1\right)}{1+C R\left(M N P, T_{0}, T-1\right)}
$$

respectively, where $\mathrm{CR}\left(M N P, T_{0}, T-1\right)$.

We compute the cumulative return of the portfolios for Dec-Jun $P i, \ldots$, May-Nov Pi. The cumulative return of the composite is the average cumulative return on the six rolling-over portfolios defined as

$$
\frac{1}{6}\left[C R\left(\operatorname{Dec}-J u n P i, T_{0}, T\right)+\ldots+C R\left(M a y-N o v P i, T_{0}, T\right)\right.
$$

and the daily return is computed using Equation (5).

\section{RESULTS}

We rank the stocks by (i) the return of the previous six months, (ii) the CAPM alpha and (iii) the FamaFrench alpha, applying the method used in the previous section to obtain the time series of daily returns of the six rolling-over portfolios and the composite return.

\subsection{Daily Portfolio Returns}

Tables 2A-2C report the average daily returns of the portfolios constructed based on the Fama-French alphas, the CAPM alphas and the returns of the previous six months, respectively. The t-statistics are reported in parentheses. The results for the composites show that the risk-adjusted momentum strategies 
have generated persistent profits. The average returns of all the portfolios are significantly different from zero except for portfolio P10. As expected, the average returns of portfolios P1, P2, .., P10 are in descending order. The average daily returns of portfolio P10 (close to zero) are much lower than the returns of the other portfolios. In particular, the average daily returns of portfolio P1 (past winners) and the average daily returns of market-neutral portfolio MNP are as high as $0.06 \%$, which is equivalent to an annualized return of around $16 \%$. The average daily returns of portfolios with the same ranking, but different starting months, do not show much difference. Note also that the average daily return of the six-month-returns-ranked composite MNP is higher than that of the CAPM-alpha-ranked and the Fama-French-alpha-ranked composites.

\section{2. $\quad$ The CAPM and the Fama-French Model for the Composites}

After obtaining the composite and the MNP returns, a capital asset pricing model and the Fama-French three-factor model are estimated for the excess daily returns of each composite. The sample period is from July 1964 to December 2013 and the results are shown in Tables 3A-3C.

A monotonic relationship between the alphas and the momentum rankings is observed. The alphas of the composites P1, P10 and MNP are significantly different from zero for all the ranking methods. The CAPM alpha and the Fama-French alpha of the composite MNP ranked by the six-month return are $0.06142 \%$ and $0.06521 \%$, respectively, which are the highest among the three ranking methods. Comparing the market betas of the composite MNP in these three approaches, we find that the sixmonth-return-ranked composite MNP leads to the smallest CAPM and Fama-French market beta. Most of the betas computed are smaller than unity, and the CAPM and Fama-French market betas of composites $\mathrm{P} 1$ and $\mathrm{P} 10$ are relatively higher than those of the other composites. This suggests that a small part of the abnormal returns of past winners should be attributed to their higher betas. However, past losers do not benefit from the slightly higher betas. The Fama-French model shows that the negative alpha of composite P10 contributes more to the return of the market-neutral portfolio than the positive alpha of composite P1.

The market beta of the composite MNP is around 0.1 for all the ranking measures. Assuming an average daily market return of $0.04156 \%$, we expect the returns of this market-neutral composite to be mainly attributable to the alpha and the specific risk. Due to market neutrality, there is no easy way to diversify the specific risk in portfolio MNP. Therefore, a mean-variance analysis is used as a complement when comparing portfolio MNP with the market.

Table 4 reports the mean and standard deviation of returns for the value-weighted market as well as those for the composite MNP according to the rankings of the Fama-French alpha, the CAPM alpha and the six-month return. Although the return-based composite MNP has a higher average daily return and a higher alpha, both the Fama-French-alpha-based and the CAPM-alpha-based portfolio MNP have lower volatilities. In all the cases, the composite MNPs have higher average daily returns and lower volatility than the market. Note that the market-neutral return should be compared with the excess market return, namely the market return minus the risk-free rate.

The Sharpe (1994) ratio

$$
S=\frac{E\left[R-R_{f}\right]}{\sqrt{\operatorname{Var}\left[R-R_{f}\right]}}
$$



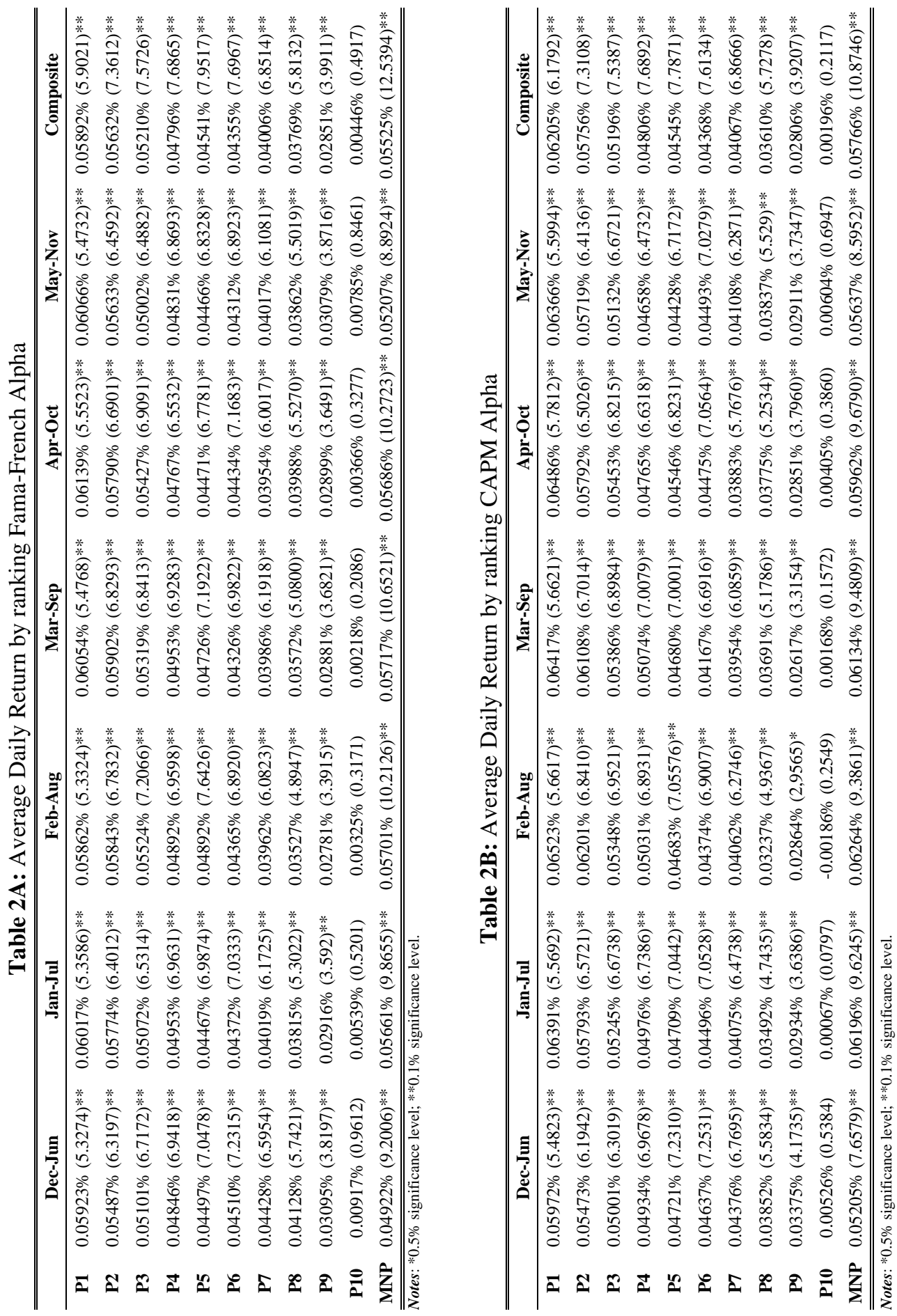


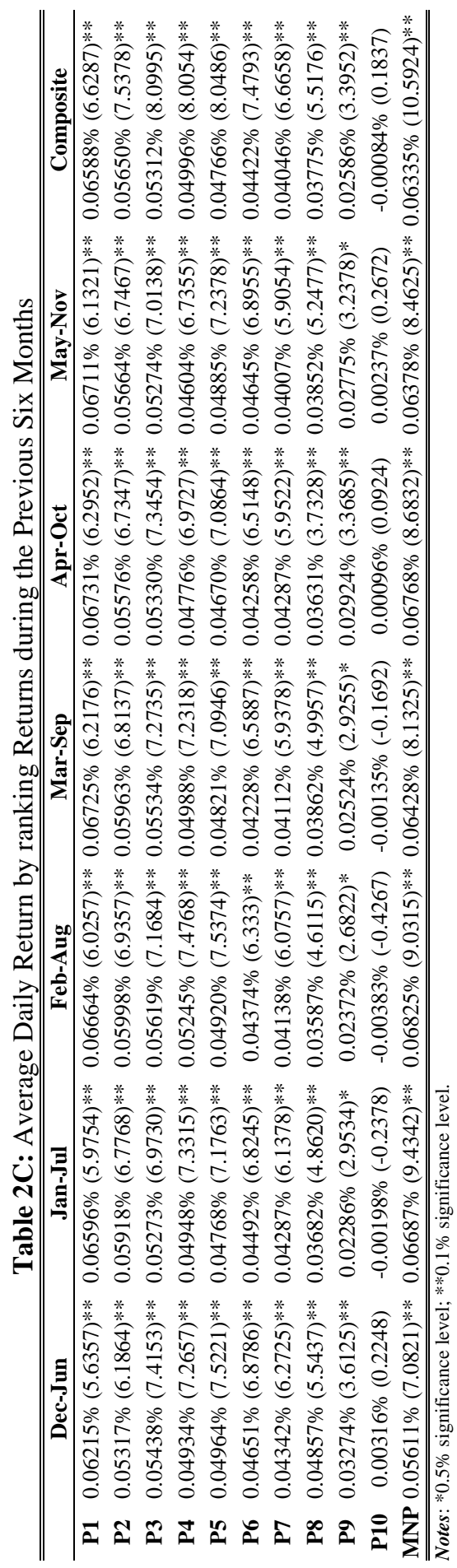

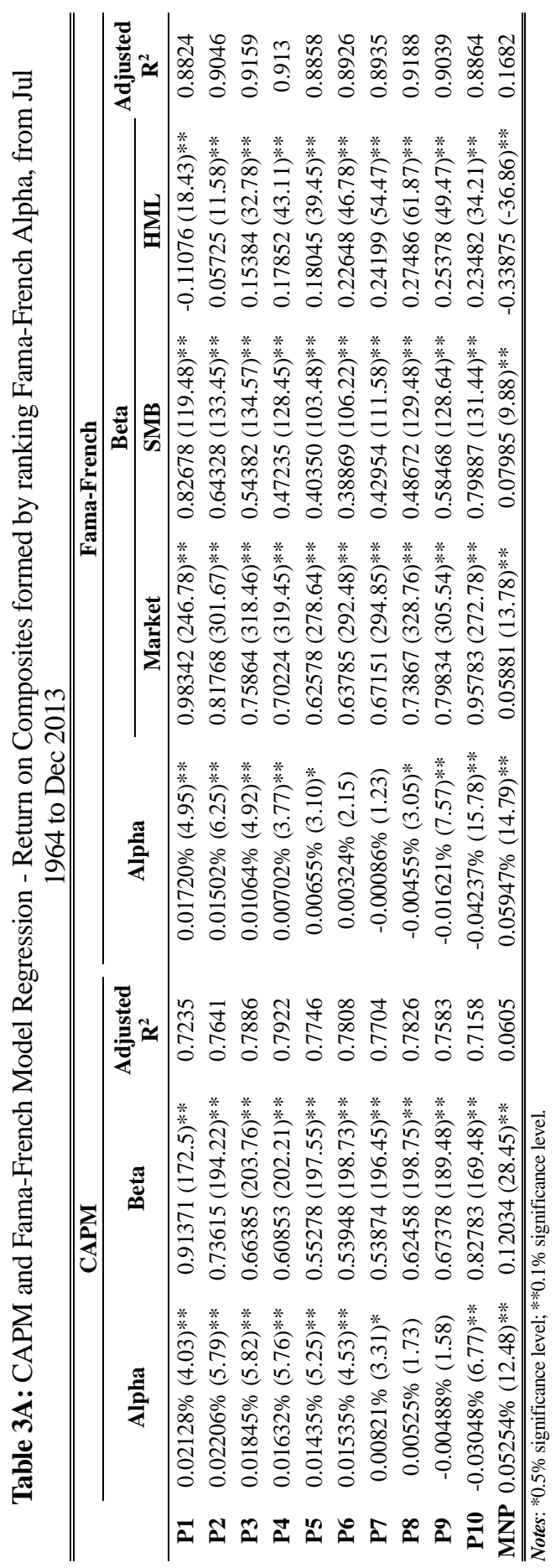



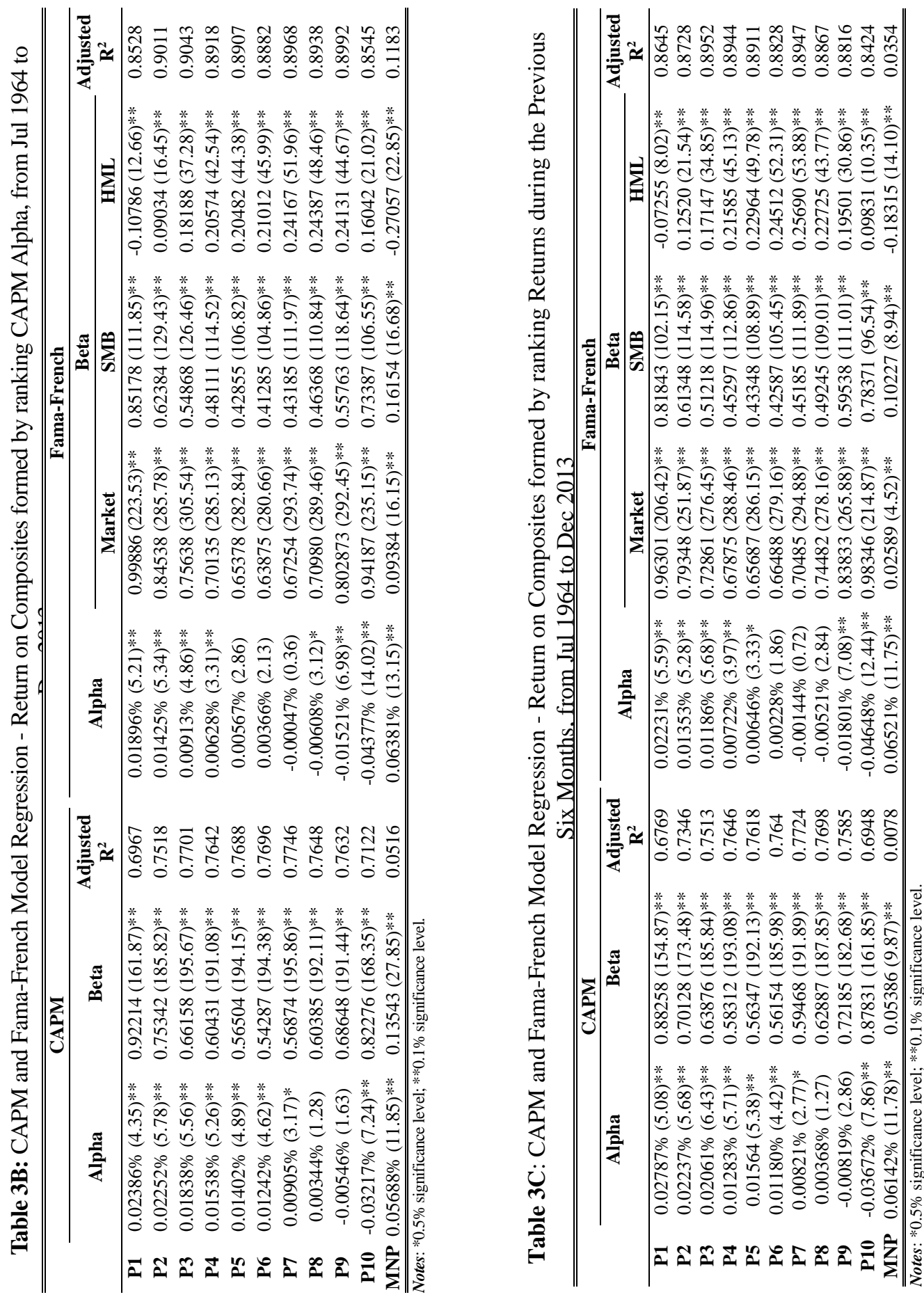
shown in Table 4 suggests that the composite MNP constructed by ranking the Fama-French alpha achieves a higher risk-adjusted return than the other two. Moreover, the Sharpe ratios (annualized) of the market-neutral portfolios are greater than 1.5, and thus are more than quintuple the market Sharpe ratio. Table 4 also shows the means, standard deviations of returns and Sharpe ratios for four sub-sample periods: July 1964-December 1979, January 1980-December 1989, January 1990-December 1999 and January 2000-December 2013. Except for the last sub-sample, all the composite MNPs according to the ranking of the Fama-French alpha lead to the highest Sharpe ratios. Noted that these high Sharpe ratios may also derived from high data frequency (daily firm-return observations) and relatively high rebanlacing frequency (six months rather than one year).

Table 4: Descriptive Statistics of Daily Returns on Composite MNP formed by ranking Fama-French Alphas, CAPM Alphas or Returns during the Previous Six Months, from Jul 1964 to Dec 2013

\begin{tabular}{|c|c|c|c|c|}
\hline & Observation & Mean & Std. Dev. & Sharpe ratio ${ }^{\dagger}$ \\
\hline & \multicolumn{4}{|c|}{ Jul 1964-Dec 2013} \\
\hline Fama-French Alpha & 11203 & $0.05428 \%$ & $0.47348 \%$ & 1.81640 \\
\hline CAPM Alpha & 11203 & $0.05862 \%$ & $0.56821 \%$ & 1.63781 \\
\hline Six-month Return & 11203 & $0.06234 \%$ & $0.63482 \%$ & 1.56892 \\
\hline \multirow[t]{2}{*}{ Excess Market Return } & 11203 & $0.01691 \%$ & $0.96542 \%$ & 0.27765 \\
\hline & \multicolumn{4}{|c|}{ Jul $1964-$ Dec 1979} \\
\hline Fama-French Alpha & 3884 & $0.04191 \%$ & $0.40545 \%$ & 1.63422 \\
\hline CAPM Alpha & 3884 & $0.04792 \%$ & $0.52351 \%$ & 1.44717 \\
\hline Six-month Return & 3884 & $0.04429 \%$ & $0.58485 \%$ & 1.19733 \\
\hline \multirow[t]{2}{*}{ Excess Market Return } & 3884 & $0.00515 \%$ & $0.75184 \%$ & 0.10829 \\
\hline & \multicolumn{4}{|c|}{ Jan 1980-Dec 1989} \\
\hline Fama-French Alpha & 2528 & $0.05556 \%$ & $0.29417 \%$ & 2.98510 \\
\hline CAPM Alpha & 2528 & $0.05922 \%$ & $0.33526 \%$ & 2.79311 \\
\hline Six-month Return & 2528 & $0.06526 \%$ & $0.39773 \%$ & 2.59417 \\
\hline \multirow[t]{2}{*}{ Excess Market Return } & 2528 & $0.03088 \%$ & $0.95691 \%$ & 0.51007 \\
\hline & \multicolumn{4}{|c|}{ Jan 1990-Dec 1999} \\
\hline Fama-French Alpha & 2528 & $0.08913 \%$ & $0.43523 \%$ & 3.23803 \\
\hline CAPM Alpha & 2528 & $0.08889 \%$ & $0.47345 \%$ & 2.96844 \\
\hline Six-month Return & 2528 & $0.08604 \%$ & $0.49668 \%$ & 2.73890 \\
\hline \multirow[t]{2}{*}{ Excess Market Return } & 2528 & $0.04813 \%$ & $0.81850 \%$ & 0.92972 \\
\hline & \multicolumn{4}{|c|}{ Jan $2000-$ Dec 2013} \\
\hline Fama-French Alpha & 2263 & $0.03453 \%$ & $0.71846 \%$ & 0.76287 \\
\hline CAPM Alpha & 2263 & $0.04235 \%$ & $0.85874 \%$ & 0.77374 \\
\hline Six-month Return & 2263 & $0.06307 \%$ & $0.96387 \%$ & 1.03872 \\
\hline Excess Market Return & 2263 & $-0.01387 \%$ & $1.37314 \%$ & -0.16438 \\
\hline
\end{tabular}

Notes: $\uparrow$ The Sharpe ratios are annualized

The cumulative returns also reflect the performance of the market-neutral portfolios (MNP). Figures 1A-1C plot the cumulative returns (on a logarithmic scale) on the composites P1, P10 and MNP for the period from July 1964 to December 2013. Excluding the dot-com bubble burst in the first half of 2000, the composite MNPs consistently outperform the market. Our market-neutral composites survive the stock market crashes of 1973-74, 1987 and 2008. Composite P1 rises more than composite P10 during the dot-com bubble due to the exceptional performance of the high-tech stocks listed on NASDAQ. 
Figure 1A: Cumulative Returns (in Logarithmic Scale ${ }^{7}$ ) on the Composite formed by ranking FamaFrench Alpha, from Jul 1964 to Dec 2013

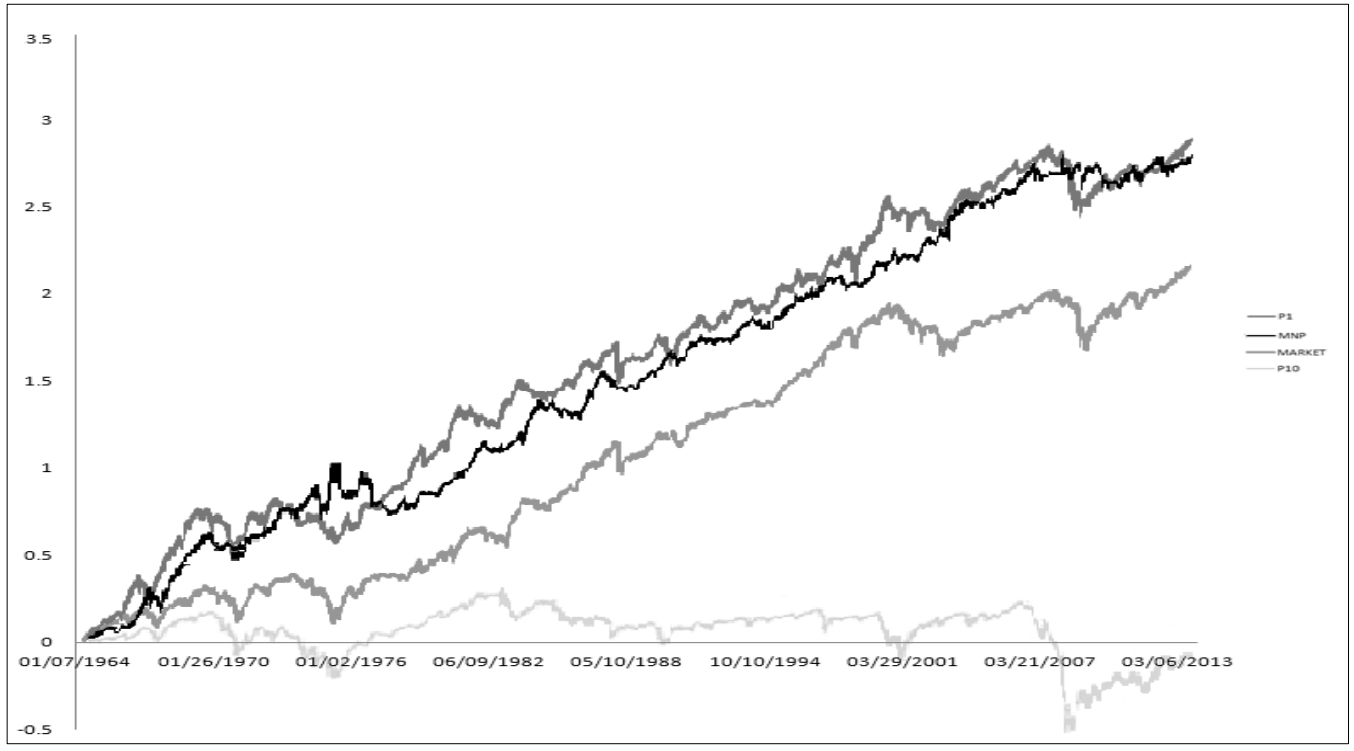

Figure 1B: Cumulative Returns (in Logarithmic Scale ${ }^{8}$ ) on the Composite formed by ranking CAPM Alpha, from Jul 1964 to Dec 2013

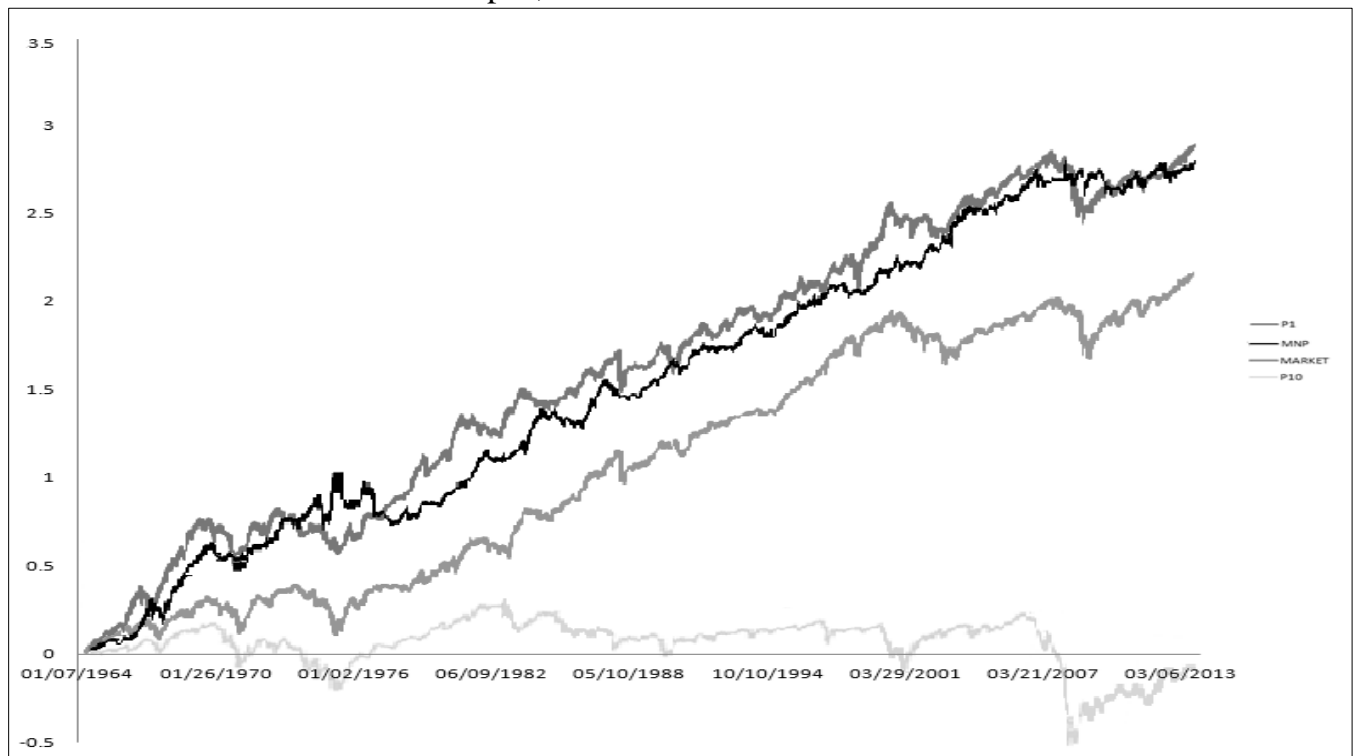

${ }^{7}$ The cumulative return is plotted on $\mathrm{y}$-axis in logarithmic scale, i.e. $\mathrm{y}$-coordinate equals to $\log _{10}\left[1+\mathrm{CR}\left(\mathrm{P}, \mathrm{T}_{0}, \mathrm{~T}\right)\right]$. For instant, $\mathrm{y}=0$ represents $\mathrm{CR}\left(\mathrm{P}, \mathrm{T}_{0}, \mathrm{~T}\right)=0$ while $\mathrm{y}=3$ represents $\mathrm{CR}\left(\mathrm{P}, \mathrm{T}_{0}, \mathrm{~T}\right)=10^{3}-1$

${ }^{8}$ The cumulative return is plotted on $\mathrm{y}$-axis in logarithmic scale, i.e. $\mathrm{y}$-coordinate equals to $\log _{10}[1+\mathrm{CR}(\mathrm{P}, \mathrm{T}, \mathrm{T})]$. For instant, $\mathrm{y}=0$ represents $\mathrm{CR}\left(\mathrm{P}, \mathrm{T}_{0}, \mathrm{~T}\right)=0$ while $\mathrm{y}=3$ represents $\mathrm{CR}\left(\mathrm{P}, \mathrm{T}_{0}, \mathrm{~T}\right)=10^{3}-1$ 
Figure 1C: Cumulative Returns (in Logarithmic Scale ${ }^{9}$ ) on the Composite formed by ranking by Returns during the Previous Six Months, from Jul 1964 to Dec 2013

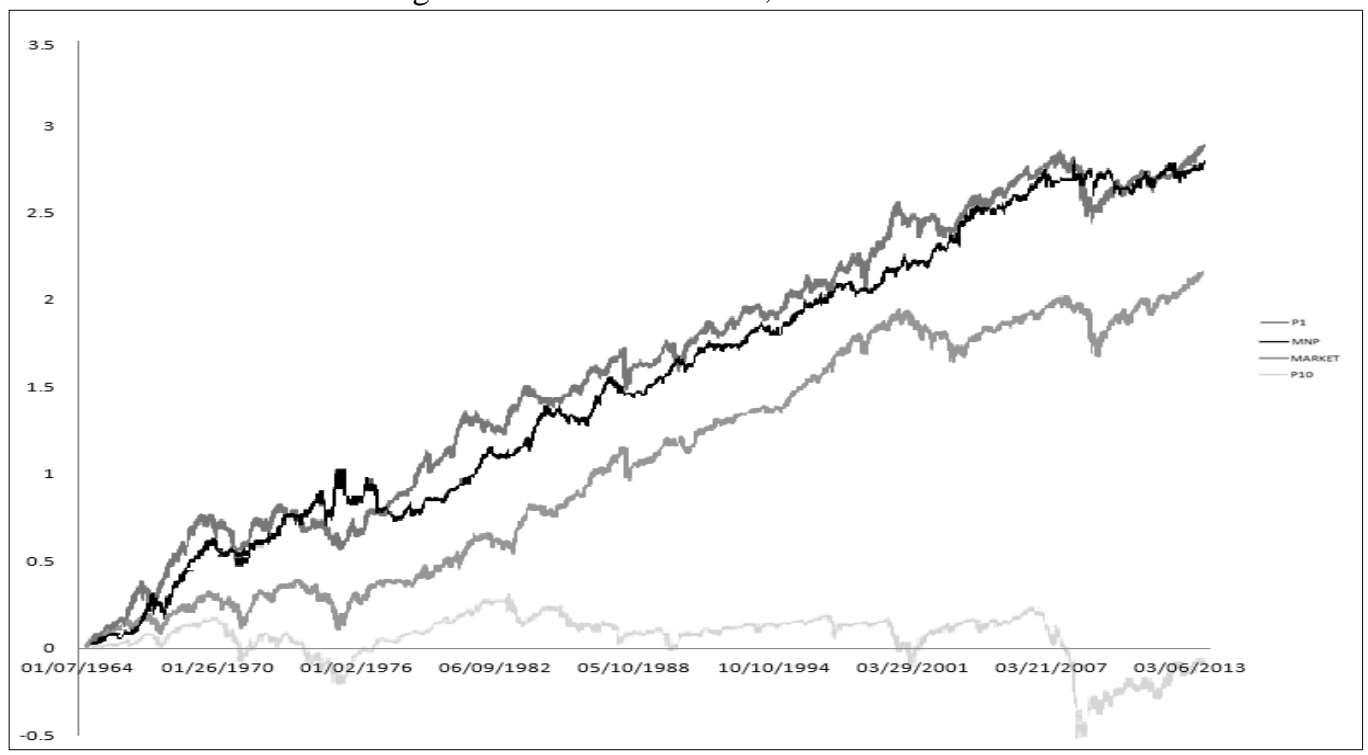

\section{ROBUSTNESS CHECKS}

To determine whether the momentum profits are due to data mining, we extend our analysis by evaluating several sub-sample periods. Specifically, the holding period returns, the CAPM alphas and the Fama-French alphas are estimated over four different sub-periods: July 1964-December 1979, January 1980-December 1989, January 1990-December 1999 and January 2000-December 2013. ${ }^{10}$ The results for the composites constructed by ranking the Fama-French alphas are shown in Tables 5A5D. Note that there is also a monotonic relationship between the momentum rankings and the measures of returns. Comparing composites P1 and P10 with the other composites, we find that both the past winners and the past losers typically have higher market betas, higher SMB betas and lower HML betas than the others. Furthermore, the estimated alpha coefficients in the Fama-French regressions lend support to the fact that the past losers in portfolio P10 underperform the market in a greater magnitude than the winning magnitude of the past winners in portfolio P1. For the CAPM alphas, it varies from decade to decade. Table 5D reports the performance of composites in recent years. It is shown that the market-neutral portfolio (MNP) still outperforms the market and has a low market beta. Note that the Fama-French market betas of the market-neutral composite in recent years are lower than those in the past three decades.

\footnotetext{
9 The cumulative return is plotted on $y$-axis in logarithmic scale, i.e. $y$-coordinate equals to $\log _{10}[1+C R(P, T, T)]$. For instant, $y=0$ represents $\mathrm{CR}\left(\mathrm{P}, \mathrm{T}_{0}, \mathrm{~T}\right)=0$ while $\mathrm{y}=3$ represents $\mathrm{CR}\left(\mathrm{P}, \mathrm{T}_{0}, \mathrm{~T}\right)=10^{3}-1$

${ }^{10}$ For simplicity, the data series of 1960 s is included in the period of 1970 s. To check robustness, we further divide this period into July 1964 - December 1969 and Jan 1970 -December 1979 respectively. Our primary results are essentially the same. These results are not reported, but are available upon request.
} 

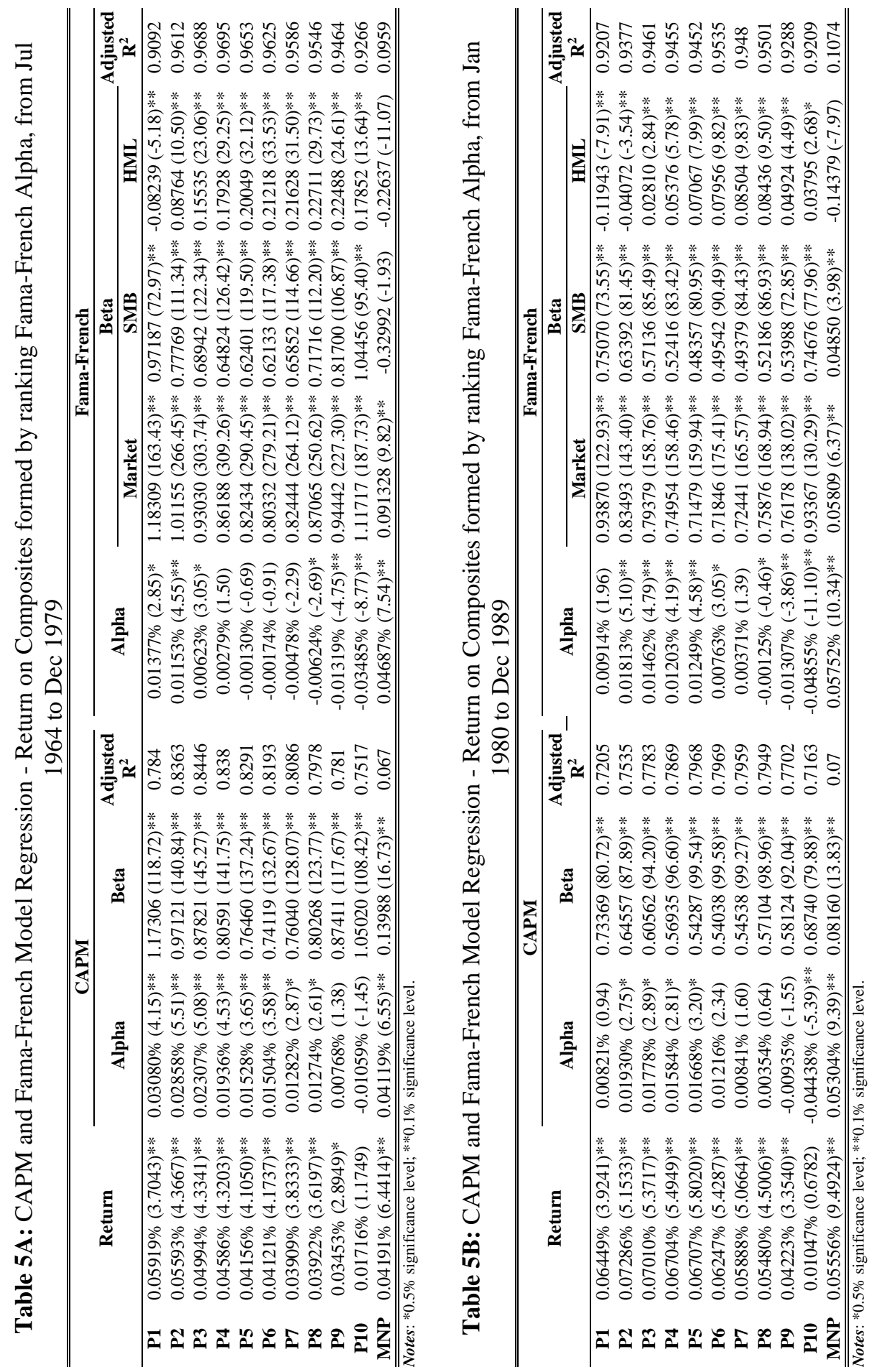


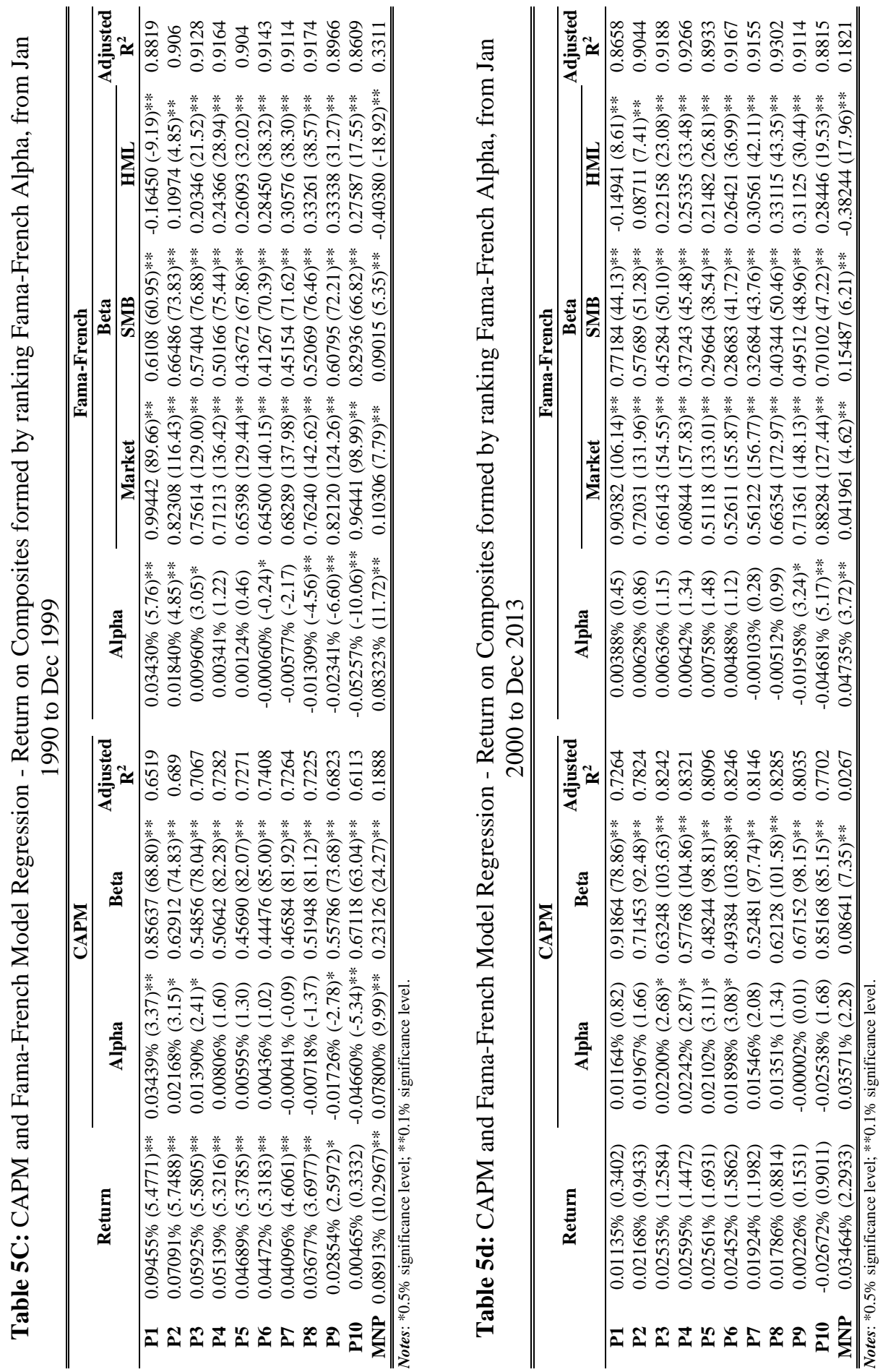




\section{CONCLUSION}

The existing momentum strategies simply rank stocks by their past returns without controlling for market- and firm-specific risks. This paper evaluates the profitability of momentum strategies in the US stock market by selecting stocks according to the values of the alphas of the CAPM and the FamaFrench regressions. The alpha estimates are used as they are adjusted for market- and firm-specific risks. It is found that significant profits and high Sharpe ratios can be obtained by employing our risk-adjusted momentum strategy. The annualized average return of the market-neutral portfolio that buys winners and sells losers is as high as $16 \%$. In particular, the market-neutral portfolios constructed by ranking the CAPM alpha and the Fama-French alpha have higher Sharpe ratios than the portfolios constructed by simply ranking the past returns. The beta of the market-neutral portfolio is found to be low. Finally, it is found that the risk-adjusted momentum profits are robust to the stock market crashes of 1973-74, 1987 and 2008. Our results suggest that risk variables, such as market- and firm-specific risks, cannot explain the momentum profits, which is inconsistent with the existing risk-based explanation of momentum. For future research along this line, one can extend our study to the period beyond 2008 to see the effect of quantitative easing on the profitability of the risk-adjusted momentum returns.

\section{ACKNOWLEDGEMENT}

We would like to thank Julan Du, Liping Lu and Jun Zhang for helpful discussions and comments. Zhe Fei provided excellent research assistance. Any remaining errors are ours. This research is supported by the Fundamental Research Funds for the Central Universities, and the Research Funds of Renmin University of China (13XNJ003).

\section{REFERENCES}

Barberis, N., Shleifer, A., \& Vishny, R. (1998). A model of investor sentiment. Journal of Financial Economics, 49, 307-343.

Chan, K. C., Hameed, A., \& Tong, W. (2000). Profitability of momentum strategies in the international equity markets. Journal of Financial and Quantitative Analysis, 35(2), 153-172.

Chong, T. T. L., \& Ip, H. T. S. (2009). Do momentum-based strategies work in emerging currency markets. Pacific-Basin Finance Journal, 17(4), 479-493.

Chordia, T., \& Shivakumar, L. (2002). Momentum, business cycle and timevarying expected returns. Journal of Finance, 57(2), 985-1019.

Daniel, K., \& Titman, S. (1999). Market efficiency in an irrational world. Financial Analyst Journal, $55(6), 28-40$.

Daniel, K., Hirshleifer, D., \& Subrahmanyam, A. (1998). Investor psychology and security market under- and overreactions. Journal of Finance, 53(6), 1839-1885.

Fama, E., \& French, K. (1993). Common risk factors in the returns on stocks and bonds. Journal of Financial Economics, 33(1), 2-56.

Fama, E., \& French, K. (1996). Multifactor explanations of asset pricing anomalies. Journal of Finance, $51(1), 55-84$.

Fama, E., \& French, K. (2004). The capital asset pricing model: Theory and evidence. Journal of Economic Perspectives, 18(3), 25-46.

Grinblatt, M., \& Moskowitz, T. (1999). Do industries explain momentum? Journal of Finance, 54(4), 1249-1290. 
Grinblatt, M., \& Moskowitz, T. (2003). An analysis of covariance risk and pricing anomalies. Review of Financial Studies, 16(2), 417-457.

Grundy, B. D., \& Martin, J. S. (2001). Understanding the nature of the risks and the source of the rewards to momentum investing. Review of Financial Studies, 14(1), 29-78.

Hong, H., \& Stein, J. C. (1999). A unified theory of underreaction, momentum trading, and overreaction in asset markets. Journal of Finance, 54(6), 2143-2184.

Jegadeesh, N., \& Titman, S. (1993). Returns to buying winners and selling losers: Implications for stock market efficiency. Journal of Finance, 48(1), 65-91.

Jegadeesh, N., \& Titman, S. (2001). Profitability of momentum strategies: An evaluation of alternative explanations. Journal of Finance, 56(2), 699-720.

Jegadeesh, N., \& Titman, S. (2002). Cross-sectional and time-series determinants of momentum returns. Review of Financial Studies, 15(1), 143-157.

Lesmond, D. A., Schill, M. J., \& Zhou, C. (2004). The illusory nature of momentum profits. Journal of Financial Economics, 71(2), 349-380.

Lewellen, J. (2002). Momentum and autocorrelation in stock returns. Review of Financial Studies, 15(2), 533-564.

Sagi, J. S., \& Seasholes, M. S. (2007). Firm-specific attributes and the cross section of momentum. Journal of Financial Economics, 84(2), 389-434.

Sharpe, W. F. (1994). The Sharpe ratio. Journal of Portfolio Management, 21(1), 49-58. 